\title{
EPIDEMIOLOGIA DA INFECÇÃO PELO VÍRUS DA LEUCOSE ENZOÓTICA BOVINA (LEB)
}

\author{
José WiLTON PINHEIRO JUNIOR ${ }^{1}$, MARIA EVÓdia DE SOUZA², WAGNNER JOSÉ NASCIMENTO PORTO ${ }^{3}$, \\ NAIR SILVA CAVALCANTI LIRA ${ }^{4}$, RINALDO APARECIDO MOTA ${ }^{1}$ \\ ${ }^{1}$ Professores Doutores da Universidade Federal Rural de Pernambuco, Recife, PE, Brasil. jrwilton@bol.com.br \\ ${ }^{2}$ Professora Doutora da Universidade Estadual de Alagoas e do Centro Universitário Cesmac, Arapiraca, AL, \\ Brasil. \\ ${ }^{3}$ Professor Doutor da Universidade Federal de Alagoas, Viçosa, AL, Brasil \\ ${ }^{4}$ Pós-doutoranda da Universidade Federal Rural de Pernambuco, Recife, PE, Brasil.
}

Objetivou-se com este trabalho investigar a presença de anticorpos anti-vírus da leucose enzoótica além de identificar a associação entre variáveis de manejo e soropositividade para essa infecção em bovinos no Estado de Alagoas, Brasil. Foram examinados 17 rebanhos, perfazendo um total de 341 animais, distribuídos em oito municípios. A pesquisa de anticorpos foi efetuada pela técnica de Imunodifusão em Gel de Ágar (IDGA), utilizando-se o antígeno constituído por lipopolissacarídeos e proteínas do vírus da leucose bovina.
Das 341 amostras analisadas, $95(27,8 \%)$ foram positivas e o número de focos constatados foi de 12 (70,6\%). Foram observadas diferenças significativas para as variáveis: assistência técnica $(\mathrm{p}<0,001)$, aquisição de gado recente $(\mathrm{p}=0,003)$, existência de piquete maternidade $(\mathrm{p}<0,001) \mathrm{e}$ manejo de colostro $(p<0,001)$. A infecção pelo vírus da leucose enzoótica bovina está presente na região estudada e medidas sanitárias rigorosas devem ser implementadas para controlar a disseminação do vírus, o que evitará perdas na cadeia produtiva da bovinocultura.

PALAVRAS-CHAVE: diagnóstico; epidemiologia; LEB.

\section{EPIDEMIOLOGY OF ENZOOTIC BOVINE LEUKEMIA (BLV) VIRUS INFECTION}

\section{ABSTRACT}

The purpose of this study was to investigate the presence of anti-enzootic leucosis virus antibodies and also to identify the association between seropositivity and management variables for this infection in cattle in the State of Alagoas, Brazil. A total of 17 herds were examined, totaling 341 animals, distributed in eight counties. The antibody detection was performed by the technique of agar gel immunodiffusion (AGID), using the antigen constituted of lipids and proteins from bovine leukosis virus. From the 341 samples analyzed, 95
$(27.8 \%)$ were positive and the number of outbreaks was $12(70.6 \%)$. Significant differences were observed for the variables: technical assistance $(\mathrm{p}<0.000)$, recent acquisition of animals $(\mathrm{p}=0.003)$, existence of maternity paddocks $\quad(\mathrm{p}<0.000)$, and colostrum management $(p<0.000)$. The enzootic bovine leukosis virus infection is present in the region studied and strict sanitary matters must be implemented to prevent spread of the virus, which will avoid losses in the cattle production chain.

KEYWORDS: BLV; diagnosis; epidemiology. 


\section{INTRODUÇÃO}

O rebanho bovino do país cresceu 1,5\% em 2009 em comparação com o ano anterior e somou 205,3 milhões de cabeças. Com isso, o Brasil detém o segundo maior rebanho de bovinos do mundo, ficando atrás apenas da Índia. Em 2008, após dois anos de queda, o número de cabeças de gado havia apresentado alta de $1,3 \%$ (IBGE, 2009). No senso recentemente divulgado pelo IBGE em 2009 foi identificada alta de 5,6\% na produção de leite, somando-se 29,112 bilhões de litros por ano no país.

Em Alagoas, dados do Censo Agropecuário 2006 registraram um efetivo bovino de 886.244 mil cabeças (IBGE, 2006), atingindo em 2009 uma produção de 238.229 mil litros de leite e uma produtividade de 1486 litros de leite/vaca/ano (IBGE, 2009).

O aumento da concentração de bovinos por propriedade, a introdução de material genético importado e a alteração de manejo sanitário e reprodutivo facilitaram a disseminação de diversos patógenos de grande importância sanitária para a bovinocultura leiteira (POLETTO et al., 2004). Dentre esses patógenos, destaca-se o retrovírus da leucemia bovina, responsável pela Leucose Enzoótica Bovina (LEB) (OIE, 2008).

A LEB é uma doença de grande importância econômica devido a vários fatores, como: perdas na exportação para mercados que requerem animais livres da infecção, custos com o diagnóstico e o tratamento das complicações dos animais com linfossarcomas, descarte prematuro ou morte de animais, particularmente aqueles de alto potencial genético, e condenação de carcaças em frigoríficos com serviço de inspeção veterinária (DIGIACOMO, 1992).

A introdução do Vírus da Leucose Enzoótica Bovina (VLB) em rebanhos brasileiros foi atribuída à importação indiscriminada de bovinos do hemisfério norte, por pecuaristas de gado de elite das regiões Sudeste e Sul. Uma vez estabelecida, nessas regiões, o vírus disseminou-se para as regiões Norte e Nordeste, favorecido pelo trânsito intenso de animais (ABREU et al.,1994) e principalmente pela ausência de uma política sanitária visando combater a ocorrência da doença em território nacional (GARCIA et al., 1991).
Para determinar a prevalência dessa infecção nos rebanhos bovinos brasileiros, diversos estudos foram realizados nas diversas regiões do país. No Estado do Rio Grande do Sul, FLORES et al. (1990) e MORAES et al. (1996) encontraram $20,7 \%$ e 9,2\% de animais positivos, respectivamente. No Estado do Paraná, BARROS FILHO et al. (2010) analisaram 268 bovinos leiteiros criados na região metropolitana de Curitiba e determinaram uma prevalência de 56,3\%. Na região Nordeste, no Estado da Bahia, TÁVORA \& BIRGEL (1991) observaram 16,1\% de animais positivos e MATOS et al. (2005) verificaram $41,0 \%$ de animais sororeagentes. No Estado de Pernambuco, MENDES et al. (2011) encontraram uma prevalência de $23,1 \%$ em rebanhos leiteiros. No Estado de Alagoas, BIRGEL JUNIOR et al. (1999) determinaram uma prevalência de $9,6 \%$ em bovinos criados na região de produção leiteira, sendo esse o primeiro registro da infecção no Estado. Portanto, esse novo estudo foi proposto para verificar a situação atual desta infecção, por meio da determinação da soroprevalência de anticorpos anti-vírus da leucose enzoótica em bovinos no Estado de Alagoas, Brasil, além de identificar a associação entre variáveis de manejo e soropositividade para essa infecção.

\section{MATERIAL E MÉTODOS}

O Estado de Alagoas está localizado na porção Centro-Oriental do Nordeste brasileiro, entre os paralelos $8^{\circ} 48^{\prime} 12^{\prime \prime}$ e $10^{\circ} 30^{\prime} 12^{\prime \prime}$ de latitude

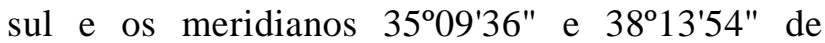
longitude oeste. Para fins de planejamento, o Estado foi dividido em três Mesorregiões: Leste Alagoano, Agreste Alagoano e Sertão Alagoano (Figura 1); e em 13 Microrregiões: Serrana do Sertão Alagoana, Alagoana do Sertão do São Francisco, Santana do Ipanema, Batalha, Palmeira dos Índios, Arapiraca, Traipu, Serrana dos Quilombos, Mata Alagoana, Litoral Norte Alagoano, Maceió, São Miguel dos Campos e Penedo, onde estão distribuídos os 102 municípios que compõem esta Unidade da Federação, que tem como capital a cidade de Maceió (UFAL, 1999; ASSIS, 2007). 


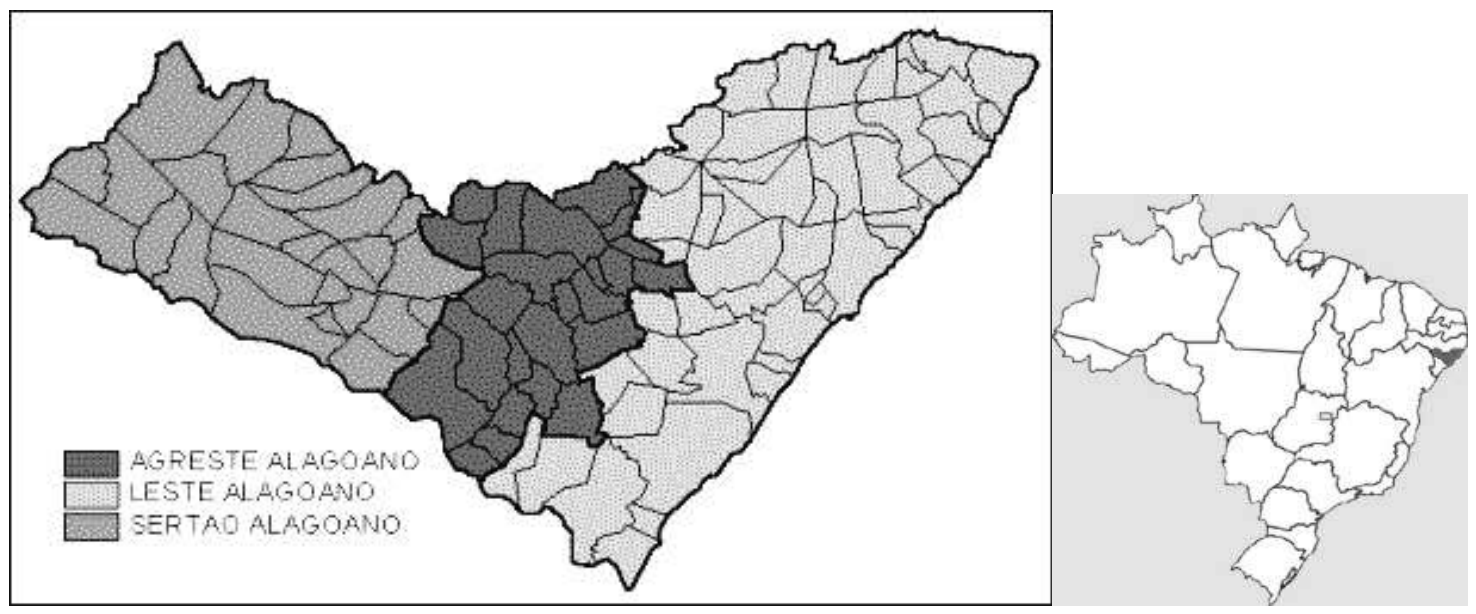

Figura 1- Mesorregiões do Estado de Alagoas

Fonte: http://www.zonasuldemaceio.com.br/alagoas/imagens/250px-Alagoas_MesoMicroMunicip.svg.png

O estudo foi desenvolvido na microrregião de Batalha, mesosertão de Alagoas, que possui um total de 96.034 bovinos distribuídos entre os municípios de Batalha (17.280), Belo Monte (10.000), Jacaré dos Homens (10.924), Jaramataia (8.012), Major Izidoro (27.547), Monteirópolis (6.035), Olho D’Água das Flores (9.536) e Olivença (6.700) (IBGE, 2006). Optou-se por trabalhar com essa microrregião por ser considerada como a bacia leiteira do estado de Alagoas.

Para se realizar este estudo epidemiológico de forma a estabelecer a prevalência de anticorpos séricos anti-VLB, utilizou-se a fórmula preconizada por THRUSFIELD (2004). Considerou-se uma prevalência estimada no país de 23,7 (FERNANDES et al., 2009), com o nível de confiança de $95 \%$ e um erro estatístico de $20,0 \%$, o que determinou uma amostra mínima de 310. Contudo, optou-se por trabalhar com 341 amostras, como margem de segurança, que foram colhidas em 17 propriedades distribuídas em oito municípios. As propriedades foram escolhidas por conveniência. Para o cálculo das amostras por propriedade utilizou-se o programa computacional WinEpiscope 2.0. Os rebanhos eram constituídos de animais de várias raças, idades, que se encontravam em diferentes estágios de lactação e eram criados em sistema intensivo ou semi-intensivo e submetidos à ordenha mecânica e/ou manual.

As amostras de sangue foram obtidas de bovinos em idade reprodutiva por punção da veia jugular, com sistema de colheita a vácuo, em tubos siliconizados com capacidade para $10 \mathrm{~mL}$. O sangue colhido foi mantido em temperatura ambiente até a retração do coágulo sanguíneo, em seguida transportadas ao laboratório sob refrigeração, onde foram centrifugadas, durante 10 minutos, a $1000 \mathrm{~g}$. O soro obtido foi transferido para tubos de polipropileno e armazenados em congelador a temperatura de $-20^{\circ} \mathrm{C}$, até o momento da realização dos testes sorológicos. $\mathrm{O}$ período da coleta foi de janeiro a abril de 2008 .

A detecção de anticorpos séricos anti- VLB foi feita por meio da prova de Imunodifusão em Gel de Ágar (IDGA), utilizando-se antígeno para diagnóstico dessa virose, produzido pelo Instituto Tecnológico do Paraná (TECPAR), segundo metodologia preconizada pelo fabricante.

Para a análise dos resultados obtidos, considerou-se a dispersão das frequências absoluta e relativa. Para identificar a associação entre variáveis de manejo e soropositividade para essa infecção, foram aplicados questionários com perguntas objetivas sobre o manejo higiênico-sanitário. A caracterização da significância entre as diferenças observadas nas frequências de animais positivos segundo o sexo, assistência técnica, última aquisição de gado, piquete maternidade e manejo de colostro foi determinada pelo teste qui-quadrado ou exato de Fisher. O nível de significância adotado foi de 5\% (ZAR, 1999). Considerou-se como foco as propriedades que apresentaram ao menos um animal reagente à prova sorológica.

\section{RESULTADOS E DISCUSSÃO}

Das 341 amostras analisadas, 95 (27,8\%) foram positivas e 246 negativas $(72,2 \%)$ (Tabela 1$)$. A prevalência de animais positivos nos rebanhos estudados variou de $5,0 \%$ a $65,2 \%$, com prevalência média de 22,3\%. Em relação aos municípios e às correspondentes taxas de prevalência da LEB em animais positivos, obtiveram-se taxas que variaram de $8,3 \%$ (1/12) a $50 \%$ (63/126). Os resultados obtidos neste estudo foram superiores aos relatados por BIRGEL et al. (1999), que encontraram uma positividade de 9,6\% no município de Batalha no Estado de Alagoas, e próximos aos relatados por MENDES et al. (2011), que observaram uma 
prevalência de 23,1\% em rebanhos leiteiros, no Estado de Pernambuco. As diferenças encontradas nesses estudos podem estar associadas às diferentes formas de manejo, tipos raciais, tecnologias empregadas (BIRGEL JUNIOR et al.,1995), além do tipo de amostragem realizado.

Em relação aos municípios, constatou-se que $100,0 \%$ possuíam propriedades com animais positivos e o número de focos foi de 70,6\% (12/17). MOLNÁR et al. (1999) realizaram estudo semelhante no Estado do Pará em 14 rebanhos criados extensivamente e descreveram que todos os rebanhos possuíam animais positivos, identificando, assim, 100,0\% de focos. Da mesma forma, CARNEIRO et al. (2003) conduziram estudo no Estado do Amazonas e identificaram 8,9\% de bovinos sororeagentes em todos os rebanhos estudados, resultados esses diferentes dos encontrados neste estudo. Apesar da diferença encontrada, o número de focos na região estudada pode ser considerado elevado, indicando que o agente está disseminado nas propriedades rurais de Alagoas. Apesar de não existirem trabalhos relatando casos clínicos de LEB em bovinos neste Estado, é importante que os médicos veterinários e produtores fiquem atentos a essa enfermidade, uma vez que o número de focos foi elevado.

Ao avaliar a significância das variáveis analisadas, observou-se associação significativa para assistência técnica $(\mathrm{p}<0,000)$, aquisição de gado recente $(\mathrm{p}=0,003)$, manejo de colostro $(\mathrm{p}<0,000)$ e existência de piquete maternidade $(\mathrm{p}<0,000)$ (Tabela 2$)$.

Tabela 1. Resultado sorológico para leucose enzoótica em bovinos da microrregião de Batalha no Estado de Alagoas, no período de janeiro a maio de 2008

\begin{tabular}{lllllll}
\hline $\begin{array}{l}\text { Sorologia } \\
\text { (IDGA) }\end{array}$ & N & F.R. (\%) & Propriedades & F.R. (\%) & Municípios & F.R. (\%) \\
\hline Negativos & 246 & 72,2 & $5 / 17$ & 29,4 & - & - \\
Positivos & 95 & 27,8 & $12 / 17$ & 70,6 & 8 & 100,0 \\
\hline Total & 341 & 100,0 & 17 & 100,0 & 8 & 100,0 \\
\hline
\end{tabular}

N = Número de animais; F.R. = Frequência Relativa.

Tabela 2. Distribuição das amostras submetidas à Imunodifusão em Gel de Agar (IDGA), segundo as variáveis associadas à presença de infecção para Leucose Enzoótica Bovina (LEB) nos rebanhos bovinos da microrregião de Batalha no Estado de Alagoas, no período de janeiro a maio de 2008

\begin{tabular}{|c|c|c|c|c|c|c|c|}
\hline \multirow{3}{*}{ Variável } & \multicolumn{4}{|c|}{ Leucose } & \multirow{2}{*}{\multicolumn{2}{|c|}{ Total }} & \multirow{3}{*}{ Valor de $\mathrm{p}$} \\
\hline & \multicolumn{2}{|c|}{ Reagente } & \multicolumn{2}{|c|}{ Não Reagente } & & & \\
\hline & $\mathrm{N}$ & $\%$ & $\mathrm{~N}$ & $\%$ & $\mathrm{~N}$ & $\%$ & \\
\hline \multicolumn{8}{|l|}{ Sexo } \\
\hline Macho & 3 & 33,3 & 6 & 66,7 & 9 & 100,0 & \multirow{2}{*}{$\mathrm{p}^{\mathrm{b}}=0,713$} \\
\hline Fêmea & 92 & 27,7 & 240 & 72,3 & 332 & 100,0 & \\
\hline \multicolumn{8}{|c|}{ Assistência técnica } \\
\hline Sim & 49 & 19,9 & 197 & 80,1 & 246 & 100,0 & \multirow{3}{*}{$\mathrm{p}^{\mathrm{a}}<0,000^{*}$} \\
\hline Não & 1 & 3,8 & 25 & 96,2 & 26 & 100,0 & \\
\hline Esporádica & 45 & 65,2 & 24 & 34,8 & 69 & 100,0 & \\
\hline \multicolumn{8}{|c|}{ Aquisição de gado recente } \\
\hline Sim & 6 & 11,3 & 47 & 88,7 & 53 & 100,0 & \multirow{2}{*}{$\mathrm{p}^{\mathrm{a}}=0,003^{*}$} \\
\hline Não & 89 & 30,9 & 199 & 69,1 & 288 & 100,0 & \\
\hline \multicolumn{8}{|c|}{ Existe piquete maternidade } \\
\hline Sim & 80 & 36,5 & 139 & 63,5 & 219 & 100,0 & \multirow{2}{*}{$\mathrm{p}^{\mathrm{a}}<0,000^{*}$} \\
\hline Não & 15 & 12,3 & 107 & 87,7 & 122 & 100,0 & \\
\hline \multicolumn{8}{|c|}{ Realiza manejo de colostro } \\
\hline Sim & 31 & 19,0 & 132 & 81,0 & 178 & 100,0 & \multirow{2}{*}{$\mathrm{p}^{\mathrm{a}}<0,000^{*}$} \\
\hline Não & 64 & 36,0 & 114 & 64,0 & 163 & 100,0 & \\
\hline
\end{tabular}

${ }^{\mathrm{a}}$ Pelo teste Qui-quadrado de Pearson; ${ }^{\mathrm{b}}$ Pelo teste Exato de Fisher; ${ }^{\mathrm{c}}$ Associação significante a 5,0\%. 
Ao analisar a variável sexo, observou-se que os machos são tão susceptíveis à infecção quanto às fêmeas $(\mathrm{p}=0,713)$. Em relação a essa variável, BIRGEL JUNIOR et al. (1995) afirmam que a diferença deve ser atribuída à influência do sistema de criação e não ao sexo, pois, nos rebanhos leiteiros, os machos, sejam eles reprodutores ou garrotes criados para a venda, são mantidos isolados, o que dificulta a transmissão horizontal do vírus.

Os fatores de risco associados à infecção pelo VLB foram analisados no Estado do Tocantins por FERNANDES et al. (2009), que concluíram que apenas o tipo de ordenha praticado nas propriedades apresentou associação significativa $(\mathrm{p}<0,05)$ e OR igual a 2,7 para ordenha manual. Entretanto, esses autores destacaram que, apesar de a variável assistência técnica não ter apresentado associação significativa, ela foi elevada $(40,1 \%)$ nas propriedades que mantinham assistência veterinária em relação às que não mantinham.

Constatou-se neste estudo maior número de animais positivos naquelas propriedades onde havia assistência técnica e aquisição de gado recente. Sabese que uma das principais formas de transmissão do vírus da LEB é horizontal, por meio do contato com materiais contaminados (luva de palpação retal, aplicadores de brinco), e a interferência do veterinário, sem os devidos cuidados higiênicos, pode ser um fator que esteja contribuindo para a ocorrência da infecção nas diversas propriedades. FERNANDES et al. (2009) relataram que a introdução negligente de animais reprodutores e/ou matrizes geneticamente qualificados e mais produtivos, de raças européias, principalmente Holandesa, sem a implantação de critérios rígidos de sanidade, cria condições favoráveis para a ocorrência da infecção pelo VLB (FERNANDES et al., 2009).

De acordo com FLORES et al. (1988), existem fatores que interferem positivamente na disseminação do agente, incluindo a presença de vários animais infectados, grande rodízio (compra e venda) de animais, criação em sistema semiintensivo e o uso rotineiro de práticas como vacinações, vermifugações e outras medidas terapêuticas, pequenas cirurgias, descorna, aplicação de brincos e palpação retal para diagnóstico de gestação.

As propriedades estruturadas com piquete maternidade e que não realizavam controle da origem do colostro, neste estudo, apresentaram índices de positividade mais elevados. Esses resultados são importantes do ponto de vista epidemiológico, pois medidas preventivas podem ser aplicadas nas propriedades para diminuir o número de animais infectados e de focos. O maior número de animais infectados naquelas propriedades que possuíam piquete maternidade deve ter sido pelo contato com pasto e água contaminados durante o parto. O uso do colostro livre de VLB é uma importante medida no controle, prevenindo a transmissão vertical (LEUZZI JUNIOR, 2001), e uma das formas de inativar esse vírus é através da pasteurização (BAUMGARTENER et al., 1976).

Considerando o elevado número de focos encontrados na região do estudo, recomenda-se que seja realizado um controle rigoroso nas propriedades para controlar o número de casos com medidas higiênico-sanitárias, rotina sorológica, sacrifício dos animais positivos e, naquelas propriedades com índice de positividade baixo, segregação do rebanho de acordo com status sorológico. Segundo FLORES et al. (1988b), o controle da infecção nas propriedades com um ou dois animais positivos poderia ser feito simplesmente pela substituição destes por descendentes negativos ou por animais soronegativos de outras propriedades. A manutenção dos animais soropositivos no rebanho coloca em risco os demais animais que, com a convivência, certamente, irão se infectar, tornando o controle ainda mais difícil.

A detecção e eliminação dos animais sorologicamente positivos constituem os pontos fundamentais no controle da infecção pelo VLB. Nesse sentido, a obrigatoriedade de exames sorológicos nos rebanhos, a exigência de soronegatividade para animais destinados a feiras e exposições, centrais de inseminação artificial, doadores de sangue para premunição e animais a serem importados são necessários na tentativa de controlar a infecção (FLORES et al., 1988b). Esse controle é necessário, uma vez que a infecção é considerada como um problema de importância sanitária e econômica, pois a presença do vírus impõe sérias restrições à exportação e importação de bovinos de alto potencial genético, além de provocar mortalidade e diminuir a produtividade dos bovinos atingidos (BRAGA et al., 1997).

\section{CONCLUSÃO}

A infecção pelo vírus da Leucose Enzoótica Bovina está presente nos bovinos da região estudada e medidas sanitárias rigorosas devem ser implementadas para se controlar a disseminação do vírus o que evitará perdas na cadeia produtiva da bovinocultura.

\section{REFERÊNCIAS}

ABREU, J.M.G.; ARAUJO, W.P.; BIRGEL, E.H. 
Prevalência de anticorpos séricos anti-Vírus da Leucose Bovina em animais criados na Bacia Leiteira de Fortaleza, Estado do Ceará. Arquivos da Escola de Medicina Veterinária da Universidade Federal da Bahia,v.17, p.67-89, 1994.

ASSIS, J.S. Atlas Escolar Alagoas: Espaço geo-histórico e cultural. Grafset: João Pessoa, 2007.

BARROS FILHO, I.R.; GUIMARÃES, A.K.; SPONCHIADO, D.; KRÜGER, E.R.; WAMMES, E.V.; OLLHOFF, R.D.; DORNBUSCH, P.T.; BIONDO, A.W. Soroprevalência de anticorpos para o vírus da leucose enzoótica bovina em bovinos criados na região metropolitana de Curitiba, Paraná. Arquivos do Instituto Biológico, v.77, p.511-515, 2010.

BAUMGARTENER, L.; OLSON, C.; ONUMA, M. Effect of pasteurization and heat treatment on bovine leukemia virus. Journal of the American Veterinary Medical Association, v.169, p.1189-1191, 1976.

BIRGEL JUNIOR, E.H.; D’ANGELINO, J.L.; BENESI, F.J.; BIRGEL, E.H. Prevalência da infecção pelo vírus da Leucose dos bovinos, em animais da raça Jersey, criados no estado de São Paulo. Pesquisa Veterinária Brasileira, v.15, p.93-99, 1995.

BIRGEL, E.H.; AYRES, M.C.C.; BIRGEL JUNIOR, E.H. Prevalência de anticorpos séricos anti-vírus da leucose enzoótica dos bovinos, em animais criados na bacia leiteira do Estado de Alagoas, Brasil. In: $3^{\circ}$ Congresso Brasileiro de Buaiatria; 1999, São Paulo. São Paulo: Arquivos do Instituto Biológico, v.66, p.129, 1999.

BRAGA, F.M.; LAAN, C.W.; HALFEN, D.C.; VIDOR, T. Avaliação de métodos de controle da infecção pelo vírus da leucose enzoótica bovina. Ciência Rural, v.27, p.635-640, 1997.

CARNEIRO, P.A.M.; ARAÚJO, W.P.; BIRGEL, E.H.; SOUZA, K.W. Prevalência da infecção pelo vírus da leucose dos bovinos em rebanhos leiteiros criados no estado do amazonas, Brasil. Acta Amazonica, v.1, p.111$125,2003$.

DIGIACOMO, R.F. The epidemiology and control of bovine leukemia virus infection. Veterinary Medicine, v.3, p.248-257, 1992.

FERNANDES, C.H.C.; MELO, L.E.H.; TENÓRIO, T.G.S.; MENDES, E.I.; FERNANDES, A.C.C.; RAMALHO, T.R.R.; MOURA SOBRINHO, P.A.; MOTA, R.A. Soroprevalência e fatores de risco da infecção pelo vírus da leucose dos bovinos em rebanhos leiteiros da região norte do estado do Tocantins, Brasil. Arquivos do Instituto Biológico,v.76, p.327-334, 2009.

FLORES, E.F.; WEIBEN, R.; PEREIRA, N.M.; PORTOLAN, J.A.B.; LIMA, P.C.R.; HERNANDEZ, L.M. Evolução sorológica da leucose enzoótica bovina em rebanhos do município de Santa Maria, RS. Revista do Centro Ciências Rurais, v.18, p.263-271, 1988a.

FLORES, E.F.; WEIBEN, R.; PEREIRA, N.M.; PORTOLAN, J.A.B.; LIMA, P.C.R.; CHIELLE, L.L.
Prevalência de anticorpos contra o vírus da leucose bovina (VLB) no rebanho leiteiro de Santa Maria, RS. Revista do Centro Ciências Rurais, v.18, p.67-73, 1988b.

FLORES, E.F.; WEIBLEN, R.; REBELATO, M.C. Aspectos epidemiológicos da infecção pelo vírus da leucose bovina (VLB) na região central do Rio Grande do Sul. Hora Veterinária, v.10, p.25-29, 1990.

GARCIA, M.; D'ANGELINO, J.L.; BIRGEL, E.H. Leucose Bovina no Brasil. Comunicações Científicas da Faculdade de Medicina Veteinária e Zootecnia da Universidade de São Paulo, v.15, p.31-39, 1991.

INSTITUTO BRASILEIRO DE GEOGRAFIA E ESTATÍSTICA (IBGE). 2006 Disponível em: http://www.ibge.gov.br. Acesso em: 03 de fev. 2011.

INSTITUTO BRASILEIRO DE GEOGRAFIA E ESTATÍSTICA (IBGE). 2009 Disponível em: http://tudonahora.uol.com.br/noticia/economia/2010/11/24 /118951/rebanho-bovino-nacional-cresce-1-5-em-2009.

Acesso em: 03 de fev. 2011.

LEUZZI JUNIOR, L.A.; ALFIERI, A.F.; ALFIERI, A.A. Leucose enzoótica bovina e vírus da leucemia bovina. Semina: Ciências Agrárias, v.22, p.211-221, 2001.

MATOS, P.F.; BIRGEL JUNIOR, E.H.; BIRGEL, E.H. Leucose enzoótica dos bovinos: prevalência de anticorpos séricos em bovinos criados na Bahia e comparação entre os resultados do teste de ELISA e da imunudifusão em gel de ágar. Brazilian Journal of Veterinary Research and Animal Science, v.42, p.171-180, 2005.

MENDES, E.I.; MELO, L.E.H.; TENÓRIO, T.G.S.; SÁ, L.M.; SOUTO, R.J.C.; FERNANDES, A.C.C.; SANDES, H.M.M.; SILVA, T.I.B. Intercorrência entre leucose enzoótica e tuberculose em bovinos leiteiros do estado de Pernambuco. Arquivos do Instituto Biológico, v.78, n.1, p.1-8, 2011.

MOLNÁR, E.; MOLNÁR, L.; DIAS, H.T.; SILVA, A.O.A.; VALE, W.G. Ocorrência da leucose enzoótica dos bovinos no Estado do Pará, Brasil. Pesquisa Veterinária Brasileira. v.19, p.7-11, 1999.

MORAES, M.P.; WEIBLEN, R.; FLORES, E.F.; OLIVEIRA, J.C.D.; REBELATTO, M.C.; ZANINI, M.; RABUSKE, M.; HÜBNER, S.O.; PEREIRA, N.M. Levantamento sorológico da infecção pelo vírus da leucose bovina nos rebanhos leiteiros do estado do Rio Grande do Sul, Brasil. Ciência Rural, v.26, p.257-262, 1996.

OFFICE INTERNATIONAL DES EPIZOOTIES (OIE). Leucosis Bovina Enzótica. Manual de la OIE sobre Animales Terrestres. Paris, 2008 Disponível em: http://www.oie.int/index.php?id=169\&L=0\&htmfile=chap itre 1.11.9.htm. Acesso em: 20 abr. 2012.

POLETTO, R.; KREUTZ, L.C.; GONZALES, J.C.; BARCELLOS, L.J. Prevalência de tuberculose, brucelose e infecções víricas em bovinos leiteiros do município de Passo Fundo, RS. Ciência Rural, v.34, p.595-598, 2004.

TÁVORA, J.P.F.; BIRGEL, E.H. Prevalência da infecção 
pelo vírus da leucose bovina em rebanhos leiteiros criados na região do pólo Itabuna, estado da Bahia. Arquivos da Escola de Medicina Veterinária da Bahia. v.14, p.164183, 1991.

THRUSFIELD, M.V. Epidemiologia Veterinária. 2. ed Roca, São Paulo, 2004. 556p.
UNIVERSIDADE FEDERAL DE ALAGOAS. Atlas Geográfico do Estado de Alagoas. Departamento de Geografia e Meio Ambiente. EDUFAL: Maceió, 1999.

ZAR, J.H. Biostatistical Analysis. New Jersey: PrenticeHall, 1999. 944p.

Protocolado em: 25 abr. 2012. Aceito em 14 fev. 2013. 